\title{
Metallurgical Analysis of Fatigue Failure in Submerge Chain Conveyor
}

\author{
Abinhot Sihotang1, Meilinda Nurbanasari²,* , Abdurrachim ${ }^{3)}$, M. Pramuda Nugraha Sirodj ${ }^{2}$ and Septa Hadi Mahaputra $^{2)}$ \\ ${ }^{1}$ Department of Civil Engineering, Institut Teknologi Nasional Bandung, Indonesia \\ ${ }^{2}$ Department of Mechanical Engineering, Institut Teknologi Nasional Bandung, Indonesia \\ ${ }^{3}$ Department of Mechanical Engineering, University of Pasundan, Bandung, Indonesia \\ *Corresponding Author \\ ORCID: 0000-0002-4947-4050 (Meilinda)
}

\begin{abstract}
Ash handling unit is one of the crucial part of the operation of a coal fired power plant (CFPP). This paper focused on the investigation of shackle chain failure in ash handling unit of a $600 \mathrm{MW}$ CFPP. The failure caused disruption to the operating system of the CFPP. To improve the chain system in order to prevent similar failure in the near future, the metallurgical failure analysis was conducted on failed shackle chain through crack observation using optical and electron microscope and Vickers hardness test. Crack surface observation of failed shackle chain using Scanning Electron Microscope (SEM) revealed that the failure of shackle chain was primarily due to the fatigue failure which was proven by the presence of beachmarks. In addition, there were two initial cracks which were caused by pitting corrosion. The clearance (gap) occurred in the bolt connection system caused the fatigue load which in turn resulted in failure to the CFPP operation. This research suggested preventive measures to be taken to avoid similar problem in the future.
\end{abstract}

Keywords: Fatigue, Shackle Chain, Corrosion, Gap

\section{INTRODUCTION}

Ash handling unit in a coal fired power plant (CFPP) has an important function to support the whole operating system. Fly ash and bottom ash are generated from coal combustion process in CFPP. Fly ash is actually a fine particulate matter emitted from the coal burning which is co-emitted with the flue gas. Fly ash should be collected in a particulate matter emission control device such as electrostatic precipitator (ESP). Bottom ash has a larger particle size than fly ash, and it is generally deposited at the bottom of the boiler furnace during the combustion process. It is non-combustible and it accumulates in ash hoppers below the boilers. Those two types of ash are treated differently when they are removed from the Steam Generator. Ash handling unit mainly process fly ash and bottom ashto be removed from the boiler in the main unit to be delivered to the ash storage site.

Fly ash handling systems include slurry transportation of fly ash and bottom ash and dry pneumatic transportation of fly ash. Fly ash is collected using ESP that is operated by charging the particulate matter entrained in the flue gas stream with high voltage and then electrostatically influencing those particles to the oppositely charged electrodes. The bottom ash is generally collected and crushed to produce fine powdered ash which is then mixed with water to produce slurry [1]. Ash handling systems for bottom ash include submerged drag chain conveyor (SDCC) and high-pressure water pumps. SDCC consists of a series of flight bars that are connected to a chain conveyor using shackle chain. The bottom ash is then carried away through the chute and the belt conveyor.

Component failures in ash handling unit are usually attributed to non-compliance maintenance intervals, errors during design such as material selection, assemblies or incorrect operation and environmental set-up [2-6]. There are some basic failures such as crack in full section, damage in partial section, distortion including plastic collapse, corrosion and also wear damage [2]. Chain failure may occur due to the use of the incorrect type of chain. There are five types of chains with different mechanical properties: cast iron, cast steel , forged, steel and plastic chain [7]. Thus it is crucial to select the proper chain material for the ash handling unit to avoid premature failure. The failure conditions are not expected by the industry who specify standard that critical equipment must be free of defects. Systematic failure that disturbs processes 
which in turn increases operational cost and decreases productivity should be avoided [6].

This paper reported and analyzed the failure of conveyor system occurred in bottom of ash handling unit in a CFPP located in Java Island, Indonesia. In this case, the SDCC system experienced a trip and the bottom ash expenditure operation was hampered due to the broken shackle chain which has a function to bind the fight bar to the chain. This type of damage oftenly occurs after only 1 year of use. The typical shackle chain failure was broken down into two parts. The shackle chain was manufactured following the standard provided by American Iron and Steel Institute (AISI) 4340. This failure resulted in disruption the operating system of the $600 \mathrm{MW}$ CFPP. This research helped to investigate the root cause of the damage therefore similar failures potentially occur in the future can be avoided. To our best knowledge, there has been limited study to focus on this issue therefore the systematic approach on metallurgical analysis used in this study is relevant when similar problem occurs elsewhere.

\section{METHODOLOGY}

Initially, we observed physical conditions of the shackle chain and compared between the in-use chain in a good condition and the broken one. Fig. 1 shows the visual comparison between both conditions of the shackle chain.
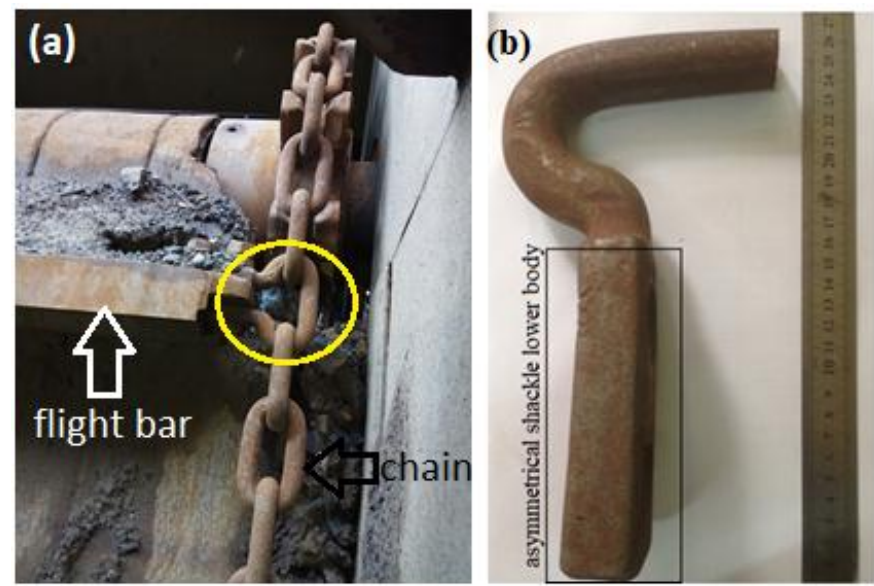

Fig 1. The shackle chain when in use as indicated by yellow circle (a) and the failed shackle chain (b).

It can be seen in Fig 1a, the shackle chain is connected to the chains and flight bar while in Fig 1b, the failed shackle chain was corroded indicated by light brown referring to iron oxides and it was teared into two sections. This failed component was taken for further investigation. The type of shackle chain used was padless shackle connectors with double bolt chain connecting shackles and the terminology used in this paper is briefly shown in Fig 2.

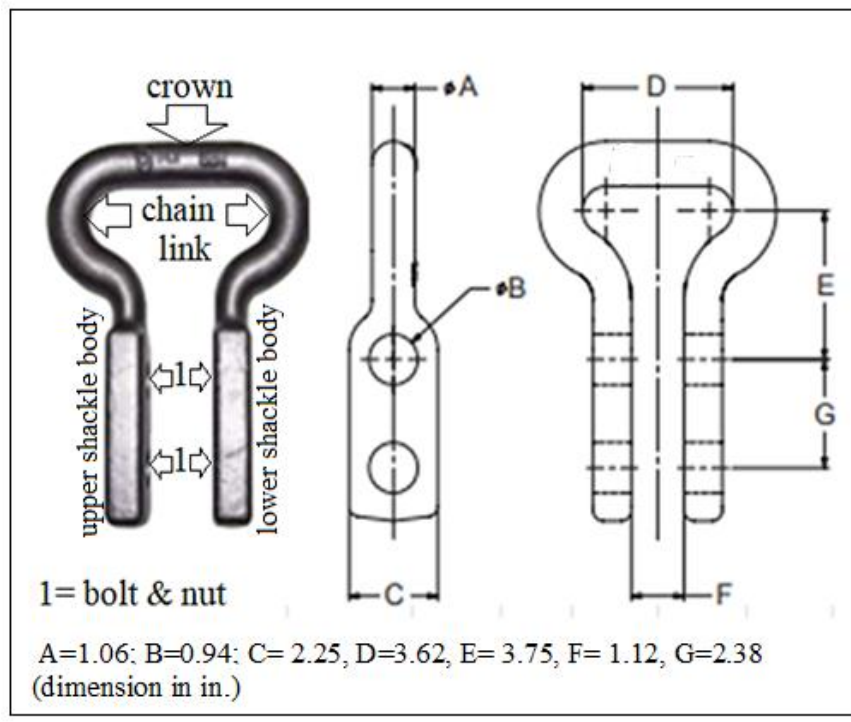

Fig. 2 Padless shackle connectors with double bolt chain connecting shackles and terminology of the shackle chain used in this paper.

To determine the cause of failure that occurs in the shackle chain, the following testings were carried out: chemical composition analysis, metallographic analysis, and hardness test. Positive Material Identification (PMI) was used for chemical composition analysis. The metallographic samples were prepared by using standard metallographic techniques, and the samples were etched with $3 \%$ nital solution to reveal the microstructures. Vickers Hardness Tester was carried out according to American Society for Testing and Materials (ASTM) E92-17 [8] with a load of 200 grams and average hardness data were collected from 5 times measurement. Evaluation of fracture morphology was observed using Scanning electron microscope (SEM) on JEOL 610-LA operated at $20 \mathrm{kV}$. There were 3 samples taken from the broken shackle chain for investigation as shown in Fig. 3. Note that, the microstructure analysis sample was used for hardness test as well.
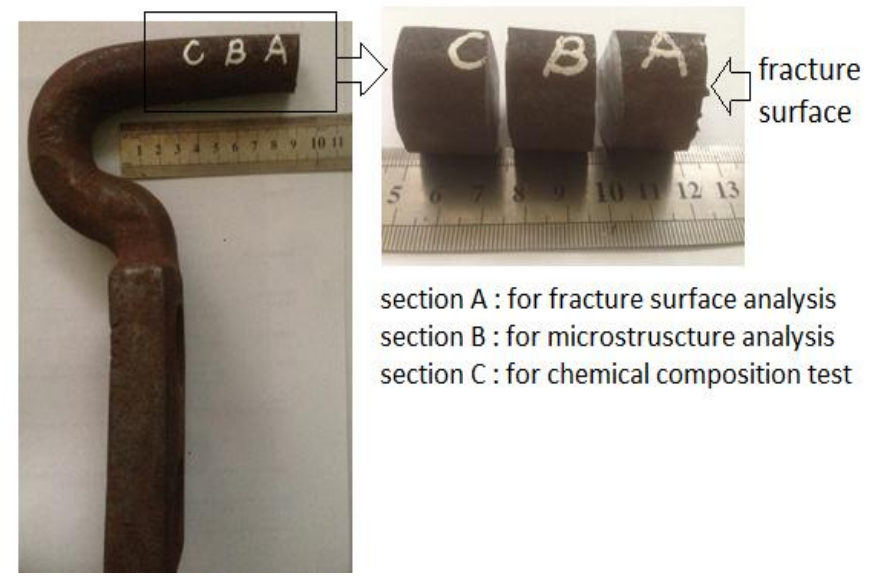

section $A$ : for fracture surface analysis section $B$ : for microstruscture analysis section $C$ : for chemical composition test

Fig.3 Three samples with each letter A, B and C, taken from the broken shackle chain for investigation 
International Journal of Engineering Research and Technology. ISSN 0974-3154, Volume 13, Number 9 (2020), pp. 2191-2195

(C) International Research Publication House. https://dx.doi.org/10.37624/IJERT/13.9.2020.2191-2195

\section{RESULTS AND DISCUSSIONS}

\subsection{Verification of the Shackle Chain Material}

Verification of the shackle chain material was done based on the result of chemical composition analysis, microstructure analysis and hardness test. Chemical composition analysis of the broken shackle chain (sample $\mathrm{C}$ in Fig 3) showed that the sample consisted of $0.35 \% \mathrm{C}, 0.52 \% \mathrm{Mn}, 0.90 \% \mathrm{Cr}, 0.16 \%$ Mo, $0.24 \% \mathrm{Si}, 0.01 \% \mathrm{Ni}$ (in wt.\%) and the remainder was iron, which satisfied the standard of AISI 4140. The average hardness of the investigated shackle chain was $372.6 \mathrm{HV}$.

The microstructure of the broken shackle chain (Fig. 4) consisted of ferrite, and tempered martensite, and indicated that the shackle chain had experienced heat treatment process. The AISI 4140 steel usually had a high hardenability, strength, and wear resistance. The elements of $\mathrm{Cr}$ and Mo are generally known as carbide formers as well as ferrite stabilizers, while Si tends to improve high temperature wear resistance of the steel $[9,10]$.

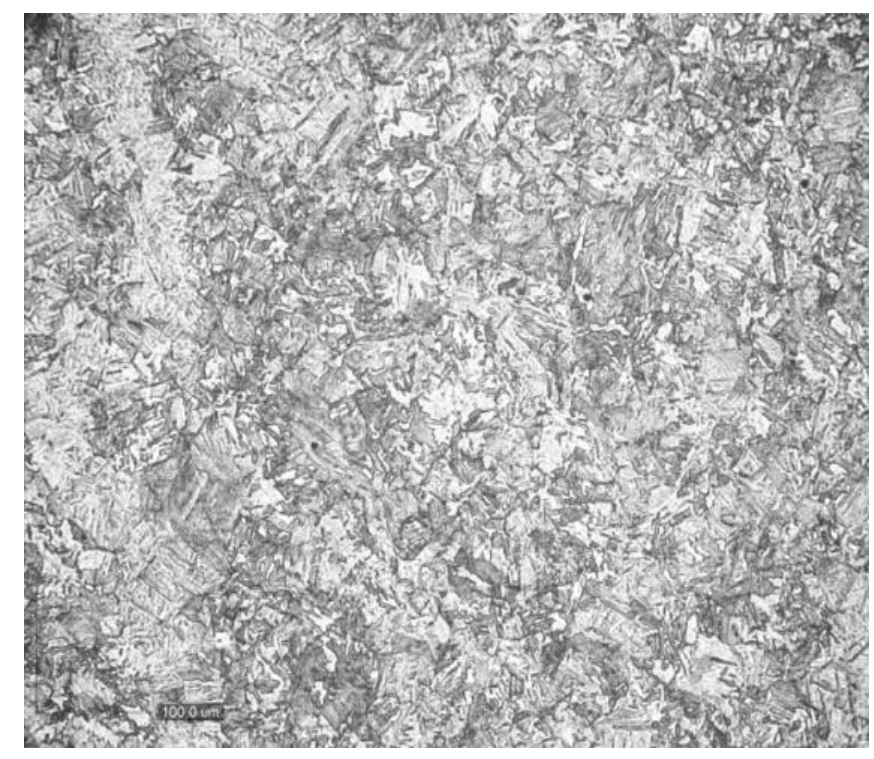

Fig. 4 Microstructure of the broken shackle chain.

\subsection{Failure Investigation}

The fracture surface morphology was carried out on sample A in Fig. 3 using stereo zoom optical microscope to identify the crack origin location and to determine a crack propagation mechanism. There was no sectioning of the sample. The optical image of a fracture surface collage of the broken shackle chain is shown in Fig 5.

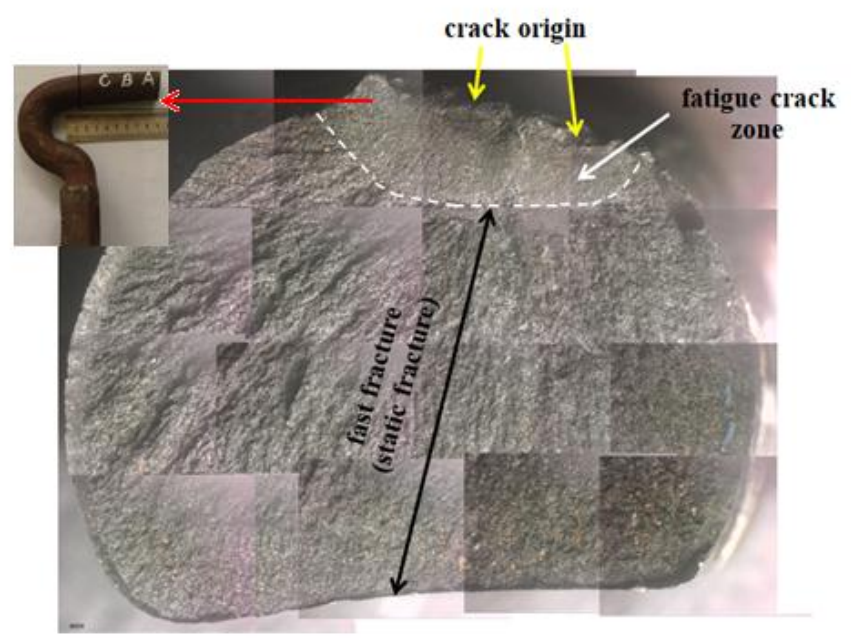

Fig.5 Optical image of a fracture surface collage made by superposition of specific areas and the white dashed line indicate the distinct fracture zones (the insert picture in the top left corner indicated by red arrow is the location of the crack origin of sample A in Fig 3.).

Fig. 5 showed the information of the location of crack origin, and the fracture surface morphology. Two locations of initial crack were observed and beach marks showing fatigue crack propagation were seen in the crown region close to the surface outer. There was a clear distinction between smooth fatigue zone and final overload. The fatigue zone was smaller than the static fracture zone.

To get detailed information on fatigue and static fracture areas, observations were conducted using SEM with a secondary electron mode. The SEM images of fracture surface are shown in Figs. 6 and 7.

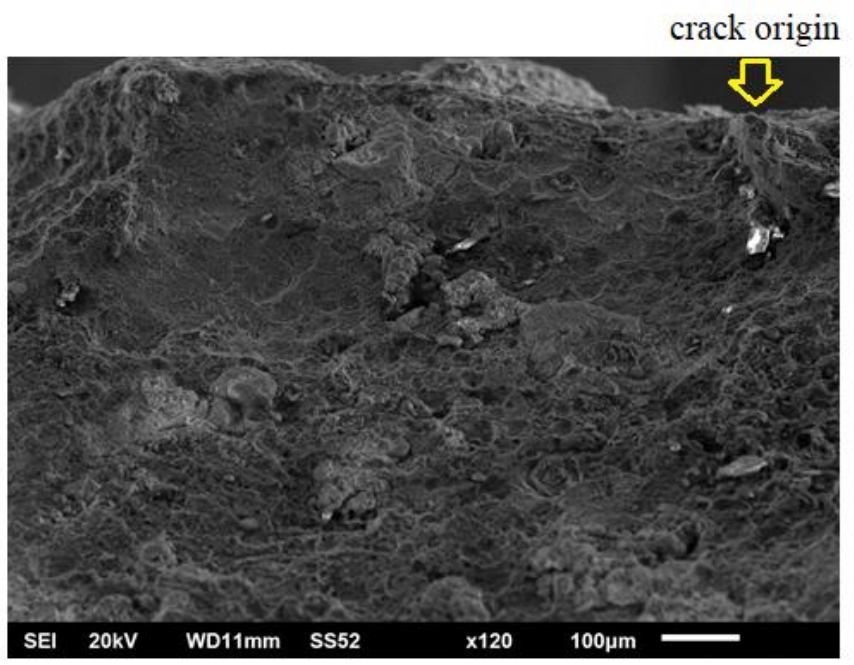

Fig.6 Secondary electron image on fatigue crack zone showing a fairly flat surface with beachmarks and crack of origin. 
SEM observation shown in Fig. 6 indicated that the fracture surface was smooth and the location of crack origins was close to outer surface of the crown area of the shackle chain. Fatigue cracks remained fairly flat in appearance even, but they had a shape similar to 'cottage cheese' which was slightly rippled [11].

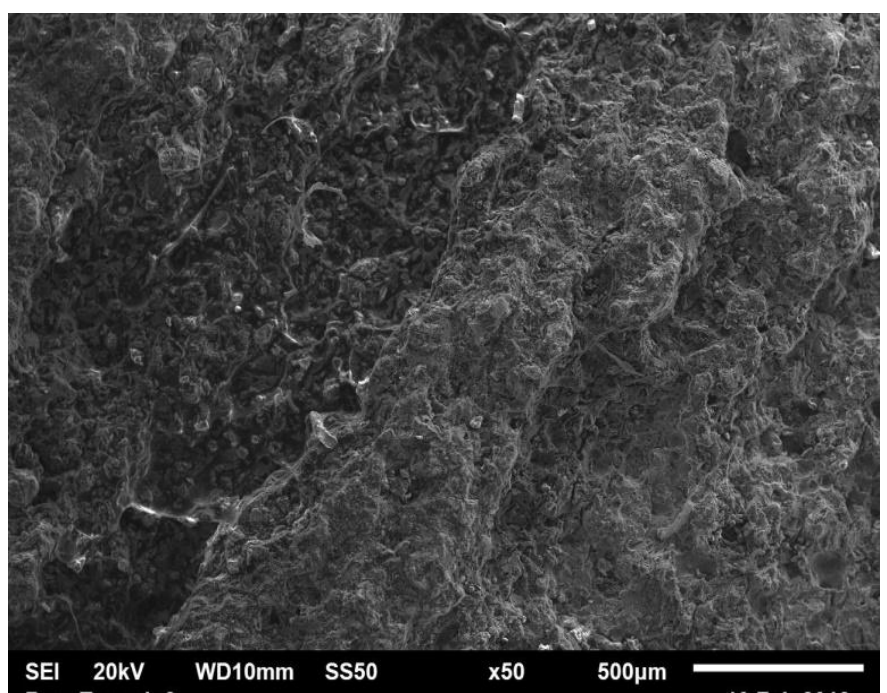

Fig. 7 Secondary electron image on the static fracture zone.

Fig 7 showed SEM image on static propagation with brittle fracture characteristic, which was indicated by transgranular crack. The small fatigue zone and the transgranular mode in static area exhibited that the material of shackle chain was brittle.

In the component that experienced a fatigue, fracture was initiated at the most sensitive point in a dynamically stressed area, typically a stress raiser, which might be a mechanical or a metallurgical process, or a combination of both. In this case, two initial cracks were initiated by the pitting corrosion in the outer surface of crown area and that pitting corrosion triggered the initial crack of the fatigue fracture. In fact, it was not surprising as the ash handling unit was in the aggressive environment where $\mathrm{Cl}^{-}$ions catalized the pitting corrosion [12-15].

Fig. 8 showed the illustration on how to determine the failure mode of the broken shackle chain based on the surface fracture from the Figs. 6 and 7.

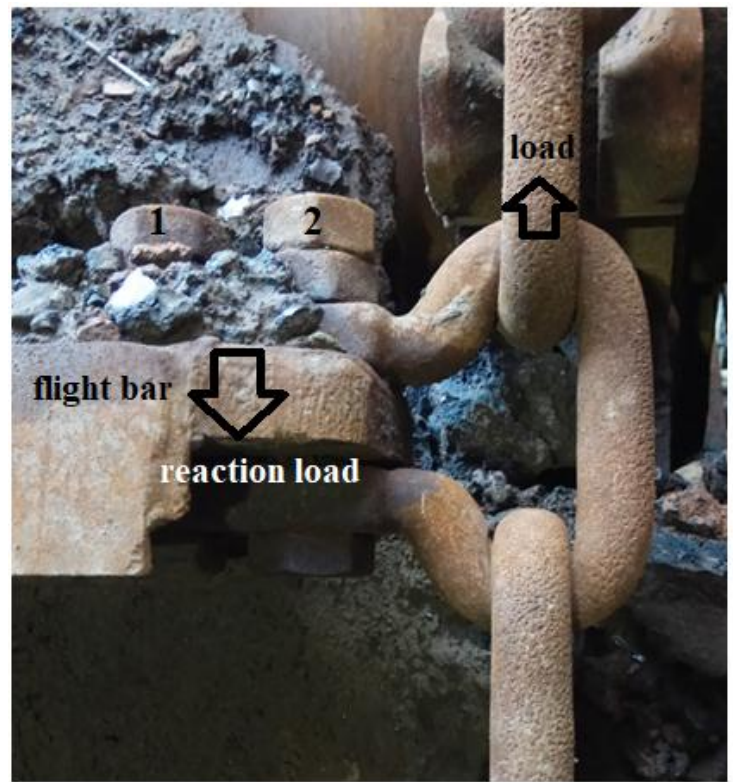

Fig. 8 Load and reaction load which occured when shackle chain was in use and the shackle chain was locked down to the flight bar by two bolts (number 1 and 2).

Fig. 8 showed the load and raction load during the shackle chain was operated. The shackle chain at the bow (chain link) was connected to the chain and at the upper / lower body was connected with a "locked" flight bar using a configuration of 2 pairs of bolt and nut (marked with "1" and "2" in Fig.8).

In a normal condition, the connection system (bolt and nut) that integrated the shackle chain with the flight bar must be tight and the load carried by the flight bar would be fully restrained by the chain link (load reaction). We expected no dynamic load acting on the shackle chain. On the other hand, if the connection system (bolt and nut) did not work well, for example due to wear or corrosion, it would cause an increase in the gap (clearance) in the connection system (bolt 1 and 2 ). This caused a relative force between the upper shackle body and the lower shackle body resulting in the moment on the crown so that the load reaction was not fully held by the chain link / bow.

The evidence showing the increase of gap (clearance) between the upper and lower body in connection systems had occurred was clearly shown in Fig.1b in which the lower body was not symmetrical. Thus the failure of the shackle chain was preceded by the occurrence of pitting corrosion on the outer surface of the crown area and the dynamic load due to clearance which occured in the bolt and nut system causing propagation of cracks and finally the fracture occured. 


\section{CONCLUSION}

Based on the aforementioned data and analyses, the following conclusions were drawn as follows:

a) The results of chemical composition analysis, hardness test and microstructure analysis exhibited that the shackle chain material complied well the standard of AISI 4140.

b) The shackle chain failure was started by pitting corrosion in the outer surface of the crown area that was triggered by an initial crack and the crack propagation was due to fatigue load. The fatigue load occurred as a result of the increasing gap (clearance) in the connection system between upper and lower shackle body.

c) To avoid similar failures in the future, routine inspections on the inner parts of the chain link (bow) should be carried out to ensure that no gradual impairment occurs, as well as in connection system to keep away from improper clearance.

\section{REFERENCES}

1. Improvements enable higher plant efficiency and efficient disposal, in Power Line : Ash Handling Techniques. 2016, India Infrastructure Publishing Pvt. Ltd. .

2. Bosnjak, S.M., et al. Failure Analysis of the Stacker Crawler Chain Link. Procedia Engineering, 10(2011), pp. 2244-2249.

3. Momčilović, D., et al., Failure Analysis of Chain Bracket: New Trends in Fatigue and Fracture, 11(1)(2011), pp. 123-126.

4. Haris, N.I., M.S. bin Wahab, and A. Talip. Failure Analysis of Conveyor Chain Links: A Case Study. Applied Mechanics and Materials, 465-466(2013), pp. 725-729.

5. Sujata, M., et al. Failure Analysis of Conveyor Chain Links. Engineering Failure Analysis, 13(6)(2006), pp. 914-924.

6. Hernandez, H.H., et al. Failure evaluations in bucket conveyor. Studies case Espacos, 38(34)(2017).

7. Otoshi, K. The Complete Guide to Chain. (1997), U.S. Tsubaki Inc.

8. E92-17, A. Standard Test Methods for Vickers Hardness and Knoop Hardness of Metallic Materials. (2017), ASTM International, West Conshohocken, PA.

9. Oluyemi, D.O., O.I. Oluwole, and B.O. Adewuyi. Studies of the Properties of Heat treated Rolled Medium Carbon Steel, Material Research 14 (2)(2011), pp. 135-141.
10. Sidney, H.A. Introduction to Physical Metallurgy 3rd ed. (2004), McGraw Hill, New Delhi

11. Moore, P. and G. Booth. 8 - Failure modes and analysis in metals, in The Welding Engineer's Guide to Fracture and Fatigue, P. Moore and G. Booth, Editors. (2015), Woodhead Publishing: Oxford. p. 95-110.

12. Lourenço, N.J., et al. Fatigue failure of a compressor blade. Engineering Failure Analysis, 15(8)(2008), pp. 1150-1154.

13. Nurbanasari, M. and Abdurrachim. Crack of a first stage blade in a steam turbine. Case Studies in Engineering Failure Analysis, 2(2)(2014), pp. 54-60.

14. Jakubowski, M. Influence of pitting corrosion on Fatigue corrosion fatigue of ship and offshore structures, Part II: load - Pit - Crack Interaction. Polish Maritime Research, 22(3 (87))(2015), pp. 57 66.

15. Ebara, R. Corrosion fatigue phenomena learned from failure analysis. Engineering Failure Analysis, 13(3)(2006), pp. 516-525. 